\title{
Functional and clinical outcome of MIPPO anterolateral plating for proximal tibia fracture both proximal one third and coronal intrarticular fracture
}

\author{
Dinesh Kumar Meena, Raghvendra Choubisa, Johney Juneja*, Anamendra Sharma
}

Department of Orthopaedics, RNT, Udaipur, Rajasthan, India

Received: 13 June 2021

Revised: 30 August 2021

Accepted: 13 August 2021

\author{
*Correspondence: \\ Dr. Johney Juneja, \\ E-mail: johney.johney2008@gmail.com
}

Copyright: () the author(s), publisher and licensee Medip Academy. This is an open-access article distributed under the terms of the Creative Commons Attribution Non-Commercial License, which permits unrestricted non-commercial use, distribution, and reproduction in any medium, provided the original work is properly cited.

\begin{abstract}
Background: The proximal tibial fractures are one of the commonest intraarticular fractures. Generally these injuries fall into two broad categories, high energy fractures and low energy fractures. The tibial plateau fractures are mostly due to high velocity road traffic accidents and fall from height, where fractures result from direct axial compression, usually with a valgus (more common) or varus moment and indirect shear forces.

Methods: This is a prospective study and includes operations by MIPPO technique that were undertaken between January 2020 till June 2021 in RNT government hospital; Udaipur. The total number of cases studied were 25 with the youngest being 25 years old and oldest 70 years old. Intraoperative complications were noted. Functional outcome was assessed using Modified Rasmussen's Criteria.

Results: Patients with fracture in our study occurred between the age of 25 to 70 years with maximum incidence involving the productive age group of 21-30 years (90\%). Majority of the patients was males- $90 \%$.

Conclusions: From the minimally invasive percutaneous plate osteosynthesis of proximal tibial fracture there is an increase in the complexity of proximal tibial fractures with increasing road traffic accident. As most of the patients sustained these fractures belong to physically highly active and productive age group, they need optimal treatment to get back to their previous work capacity and avoid long term complications like osteoarthritis. We treated all fractures in our study with MIPPO technique and found rapid healing by secondary fracture union and hence achieving strong bone union across the fracture site due to inherent benefits of less tissue damage and minimal disturbance of fracture site biology. We operated 20 proximal tibial fractures with MIPPO technique and observed rapid healing and good functional recovery.
\end{abstract}

Keywords: MIPPO, LCP, ACL, Proximal tibia

\section{INTRODUCTION}

Fractures around the knee in adults account for only $2 \%$ of all the fractures. However, the fractures of proximal tibia are very important, it being the most critical load-bearing area in the body affecting knee alignment, stability and motion. ${ }^{1}$
The majority of proximal tibia fractures are secondary to high speed velocity accidents and fall from height, where fractures results from: direct axial compression, usually with a valgus (more common) or varus moment and indirect shear forces. 
Early detection and appropriate treatment of these fractures are critical in minimizing patient disability and reducing the risk of documented complications, particularly post-traumatic osteoarthritis. Ever since initial description by Sir Astley Cooper, the earlier management included technique of traction mobilization and functional cast bracing. ${ }^{4}$ However, there was sizeable incidence of malunion, secondary osteoarthritis and nonunion. To prevent such complications internal fixation method was introduced. But initially introduced methods of internal fixation were not efficient enough to provide a stable fixation, thus requiring additional postoperative immobilization. Additional surgical trauma combined with postoperative immobilization resulted in high incidence of stiffness of knee joint and poor functional outcome.

The aim of surgical treatment of tibial plateau fracture is to restore congruent articular surfaces of the tibial condyles maintaining the mechanical axis and restoring ligamentous stability eventually can achieve functional painless and good range of motion in the knee joint. ${ }^{5}$

Operative treatment of these fractures received a boost with the advent of anti-glide plates or buttress plates. These plates served different functions depending on the fracture pattern and where they are placed. When placed anteriolaterally, they served as buttress plates to substitute for the fractured lateral plateau. Initially $4.5 \mathrm{~mm}$ implants were used which were later replaced by less bulky and easily fitting $3.5 \mathrm{~mm}$ implants and screws. A biomechanical comparative study had shown that in cancellous bone $3.5 \mathrm{~mm}$ screw exerted equivalent pull out strength as that of $4.5 \mathrm{~mm}$ and $6.5 \mathrm{~mm}$ screws. In posteriomedial aspect they serve as antiglide devices. However a high incidence of some loss of articular reduction after surgically treating lateral plateau fracture has been reported in up to $31 \%$ cases. $^{6}$

However rigid stabilization was not the only concern while treating tibial plateau fracture. Dual plating medially and laterally with a bone-stripping single anterior incision has been associated with very high rates of complications specially avascular necrosis.So to prevent soft tissue stripping better modern surgical technique using two separate incisions was introduced. ${ }^{7-9}$

The various clinical studies established that bone beneath a rigid conventional plate are thin and atropic which are prone for secondary displacement due to insufficient buttressing and secondary fractures after removal of plate, fracture site take longer period to osteosynthesis due to interruption of vascular supply to bone due to soft tissue and periosteal stripping.

But this was difficult as conventional plates needed to be accurately contoured to achieve good fixation, osteoporosis also posed the same problem of poor fixation with conventional plates. ${ }^{10}$
The advantages of so-called sub muscular plating are probably particularly important in high-energy injuries with significant soft-tissue swelling, and early results of these plates have provided encouraging results treating bicondylar fractures with a single laterally based locking plate. $^{11,12,19}$

This leads to the development of the internal fixators. PCfix I later PC fix II. As more and more concepts about biological fixation become clearer the innovation of plates progressed lead to development of less invasive stabilizing system (LISS).

Research to combine these two methods has lead to the development of the AO locking compression plate (LCP). ${ }^{20}$

Another attempt which improved the outcome came in the form of one of the first locking system with ability to insert percutaneously was less invasive stabalisation system (LISS). Its advantages included decreased vascular disruption of periosteum, higher elastic deformation of system allowing micromotion and callus formation, increased rigidity in osteoporotic bone, anatomical plate contour and avoidance of medial buttress plate to prevent varus deformityThe fixed-angle component allows for supporting the medial plateau from the lateral side, removing the need to place a plate medially for some bicondylar fractures. The locked nature of the plate avoids the need to place the plate compressed against the periosteum limiting damage to the periosteal blood supply. ${ }^{11,12,19}$

MIPPO techniques avoid direct exposure of the fracture site and transforms the implants in an internal extramedullary splint. Furthermore, MIPPO was successfully extended to complex tibial fractures, being actually indicated in all long bones complex fractures that are not suitable for intramedullary osteosynthesis.

\section{MIPPO can be structured in 4 steps or techniques:}

MIPPO technique with proximal and distal incisions. It was described by Wenda 15 that have used a femoral limited lateral approach, proximally and distally from the fracture site, with plate insertion beneath the vastus lateralis; Minimally Invasive Percutaneous Plate Osteosynthesis (MIPPO) procedure was developed for extraarticular fractures of the distal and proximal femur; the key for this technique is represented by the usage of a two-part implant, the Dynamic Condylar Screw (DCS) 14; Transarticular Approach and Retrograde Plate Osteosynthesis (TARPO) procedure was developed by Krettek 16), for the osteosynthesis of the distal femoral intraarticular fractures. Procedures that uses specific implants for MIPPO procedures (Plates with angular stability and tools for percutaneous insertion). 
MIPPO special characteristics are represented by:

The treatment purpose in minimally invasive plate osteosynthesis consists in anatomic reconstruction of the articular area, axis, rotation and length reestablishment for the metaphyseal-diaphyseal area, long plates osteosynthesis with screws fixed only distally and proximally from the fracture, bridging the comminution and with early functional rehabilitation.

Various studies results demonstrate that MIPPO and TARPO have undeniable advantages over classic techniques: fast healing, reduced complication rate, reduced primary or secondary grafting requirements, and shortening of the operative time. Moreover, TARPO procedure provides a good exposure of the knee joint.

Good results obtained by minimally invasive plate osteosynthesis are due to a fast healing by vascularization protection and also to an increased resilience to mechanical stress.

Fixation with long plates only distally and proximally from the fracture site maintains a certain instability degree that is useful for an accurate and fast healing (relative instability).

Minimally invasive plate osteosynthesis is a demanding technique, requiring a cautious intraoperative clinical and fluoroscopic control in order to reestablish limb axis, rotation and length.

The incidence of tegumentary necrosis, nonunions and infections is increased especially for the extended external and medial approach. These complications induce a decrease of the local blood flow due to excessive deperiostation and fragment devitalization. The disadvantages of the external placed plates determined authors as Krettek to introduce MIPPO technique by medial approach. ${ }^{17}$ The main advantages are represented by the ease of molding technique and the subcutaneous placement, without deperiostation or blood flow limitations. ${ }^{18}$ After alignment of the fracture by indirect reduction, the plate is introduced through a short incision beneath the skin, and pushed distally on the medial aspect of tibia. The bridging plate is initially fixed proximally, the alignment is checked using fluoroscopy and finally, the plate is fixed distally

\section{Advantages cited for MIPPO are:}

Simpler technique and easy to master. Learning curve short. No need of additional expensive instrumentation. Improved rates of fracture union. Decreased infection rate. Decreased need for bone grafting. Ideal technique for dealing with the multiply injured patients. Early mobilization of the extremity possible. Decreased incidence of refracture after plate removal.
Pre-contoured plates have several advantages like reduction of time spent for intraoperative plate contouring, facilitate limited approach when bone is not completely visualized to allow contouring and assistance in the reduction by fitting the fractured bone to precontoured plates. $^{21}$

Lateral plates must resist axial, rotational and bending forces specially when used in case of type 5 and type 6 Schatzker fractures. Locking compression plates can very well resist such forces to prevent the secondary displacements due to less than perfect contouring. In addition they also provide angular stability which increases their load bearing capacity. Every locking screw gets locked into threaded plate hole hence making a fixed angle construct. Therefore, functionally each locking screw behaves like a miniature blade plate. ${ }^{22}$

Clinical advantage of the locking plate is the ability to support the medial plateau and prevent varus collapse of bicondylar plateau fractures through a single, laterally based implant.

This new system (LCP) has been regarded as technically mature. It offers numerous fixation possibilities and has proven to worth in complex fracture situations and in osteoporosis.

The present study is therefore proposed to evaluate the efficacy of internal fixation using locking compression plate in proximal tibia fractures using minimal invasive plate osteosynthesis.

\section{Aims and objectives}

To restore the anatomy of articular surface of upper end of tibia and knee joint perfectly by operative treatment with internal fixation. Early mobilization of knee joint. To assess the union of fractures after internal fixation. To assess the range of motion of knee joint after surgical management. To compare the results with those reported in literature.

\section{Principles}

The principles of surgical management of any intra articular fracture fixation are: Anatomical reduction-to maintain joint congruity and to prevent secondary osteo arthritis. Stable internal fixation. Enbloc uplifting of depressed articular fragment and bone grafting. Early mobilization, of the joint. Defer weight bearing until complete fracture union.

\section{Tibial plateau fractures}

\section{Incidence}

Fractures of tibial plateau constitute $1 \%$ of all fractures and $8 \%$ fractures in the elderly. These fractures encompass many and varied fracture configurations that involve the medial condyle (10-23\%), lateral condyle (55-70\%) or 
both (11-30\%) with differing degrees of articular depression and displacement.

\section{Nature of violence}

It can be either direct/indirect.

\section{Direct}

Automobile accidents, which is one of most frequently encountered.

Road traffic accidents/ automobile accidents (high velocity trauma and low velocity trauma), falling from a height, Industrial accidents, valgus stress/varus stress, athletics, and assault.

\section{Indirect}

Trivial injures like: stumbling, twisting, and missing steps, etc.

\section{Fracture classification}

\section{Schatzkers classification}

Type I - pure cleavage

A wedge shaped uncomminuted fragment is split off and displaced laterally and downwards. This fracture is common in younger patients without osteoporotic bone.

\section{Type II - cleavage combined with depression}

A lateral wedge is split off, but in addition the articular surface is depressed down into the metaphysis. This tends to occur in older people with osteoporotic bone.

\section{Type III - pure central depression}

The articular surface is driven into the plateau. The lateral cortexis intact. These tend to occur in osteoporotic bone.

\section{Type IV - fractures of medial condyle}

These may be split off as a wedge or may be comminuted and depressed. The tibial spines are often involved. These fragments tend to angulate into varus.

\section{Type $V$ - bicondylar fractures}

Both tibial plateau are split off. The distinguishing feature is that the metaphysis and diaphysis retain continuity.

Type VI- plateau fracture with dissociation of metaphysis and diaphysis

A transverse or oblique fracture of the proximal tibia is present in addition to a fracture one or both tibial condyles and articular surfaces.

\section{Complications of treatment of proximal tibia fractures}

The complications occur by virtue of fracture and also after the treatment. Most of the complications are preventable. Preventive care begins with thorough examination of the injured limb.

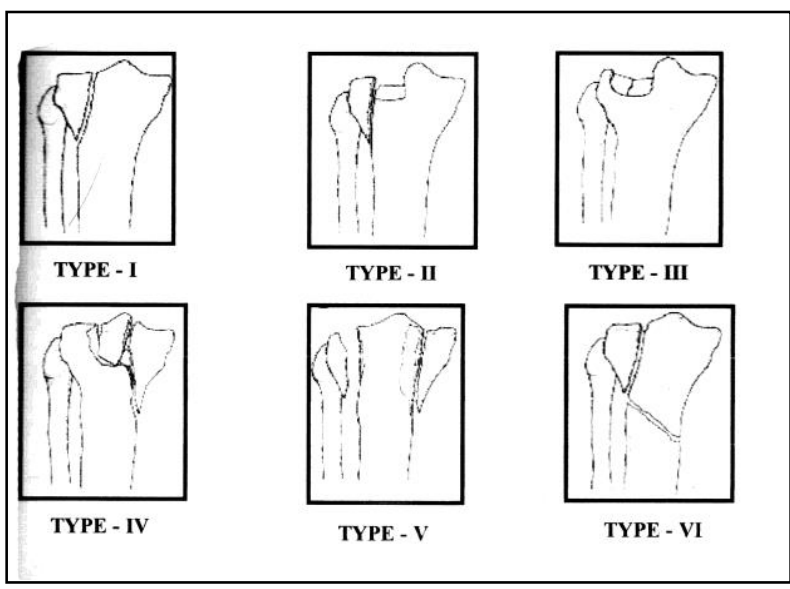

Figure 1: Schatzker's classification of tibial plateau fractures.

\section{Early complications}

Bleeding, wound infection /dehiscence - superficial or deep, sepsis, compartment syndrome, pain, swelling, knee stiffness, nerve injury (lateral politeal. N), vascular injury (anterior tibial a), loss of fracture reduction, limb length discrepancy and deep vein thrombosis

\section{Late complications}

Wound infection, knee stiffness, malunion, knee instability - varus/valgus/anterior/posterior, extensor lag, angular deformities, persisting pain/swelling, redepression, refracture, delayed union and non-union

\section{Locking compression plate (LCP)}

A further refinement of internal fixator systems, with screw heads locking firmly into the plate hole, has now been devised. This is a new plate hole configuration which brings to this most valuable innovation the advantages of conventional plating for example. Placement of a lag screw across the plate for certain fracture configurations. This is achieved through a new design, the "combination" plate hole which can accommodate either a conventional screw or the new "locking head screw (LHS)" which has a conical threaded head.

\section{Design features of $L C P$}

The locking compression plates have these LC-DCP features. 500 of longitudinal screw angulation. 140 of transverse screw angulation. Uniform hole spacing. Load (compression) and neutral screw positions. The locking 
compression plates have combination locking and compression holes that allow placement of conventional cortex and cancellous bone screws on one side or threaded conical locking screws on the opposite side of each hole. Tapered end for submuscular plate insertion, improving tissue viability. Limited-contact plate design reduces plate to bone contact limiting vascular trauma. Holes in straight plates are oriented so that the compression component of the hole is always directed towards the middle of the plate. Locking screw design. The screw design has been modified from standard $4.5 \mathrm{~mm}$ cortex screw design.

New features include: Conical screw head- facilitate alignment to provide a secure screw plate fixation.

Large core diameter- improve bending and shear strength and distribute the load over a larger area in the bone $4.0 \mathrm{~mm}$ and $5.0 \mathrm{~mm}$ locking screws, self-tapping.

The locking screws mate with the threaded plate hole to form a fixed-angle construct. The shallow thread profile of the locking screw results from large core diameter.

\section{General principles of internal fixation using LCP}

Internal fixation using a combination of locking screws and standard screws.

If a combination of cortex and locking screws is used, a cortex screw should be inserted first to pull the plate to the bone. If locking screws have been used to fix a plate to a fragment, subsequent insertion of a conventional screw in the same fragment without loosening and retightening the locking screw is NOT

\section{Recommended}

If a locking screw is used first, care should be taken to ensure that the plate is held securely to the bone to avoid spinning of the plate about the bone. Once the metaphyseal fragment has been fixed with locking screws, the fracture can be dynamically compressed using conventional screws in the DCU (Dynamic Compression Unit) portion of the LCP hole. First, use lag screws to anatomically reconstruct the joint surfaces. The behaviour of a locking screw is not the same as that of a lag screw. With the locked plating technique, the implant locks the bone segments in their relative positions regardless of how they are reduced. A plate used as a locked plate does not produce any additional compression between the plate and the bone. The unicortical insertion of a locking screw causes no loss of stability. Depending on the desired functional the locking compression plate (LCP) can be applied in three different ways: LCP as a conventional dynamic compression plate. LCP combining conventional and locked application. LCP as pure internal fixator (bridge plating)

\section{LCP as conventional plate}

The LCP can be used as conventional plate with conventional screws. It may then have one of five function; i.e, compression, bridging, buttress, protection, and tension band. With the use of an accentric drill guide, axial compression can be obtained or a lag screw can be placed through any plate hole. This classical fixation is still applicable for articular fracture and in simple type A and $\mathrm{B}$, fracture in the meta-diaphyseal area, where anatomical reduction and absolute stability is recommended and can easily be achieved without wide exposure. Other indications are closed wedge osteotomies as well as delayed and nonunions, where absolute stability is recommended. The LCP can also be used as a plate to protect a lag screw fixation. If only locking head screws are used then this could be considered to be a protecting internal fixator.

\section{LCP combining conventional and locked application}

Here both techniques are employed (combination technique) using conventional lag screws as well as locked screws.

In articular fractures requiring an anatomical reduction and fixation by interfragmentary compression lag screws may be essential for the reconstruction of any articular components. At the same time the locking head screw provides angular stability, helping to prevent secondary displacement in case of metaphyseal comminution or other bony deficiency. The term "combination" describes the combination of the two described biomechanical principle : use of a combination of interfragmentary compression and the internal-fixator method (bridging). A combination technique does not mean combining different type of screws. This hybrid use of both type of screws (standard and locked screw) can be considered in the following situations:

Reduction onto the plate in case of a residual axial malalignment of a fracture mostly in the frontal plane. Malalignment of the plate with respect to the long axis. These exist two indications for the combination technique. Articular fracture with a multifragmentary fracture extension into the diaphysis : anatomical reduction and inter fragmentary compression of the articular component, bridging of the reconstructed joint block to the diaphysis (flexible by the internal fixator method). Segmental fracture with two different fracture patterns (one simple and one multifragmentary). Compression principle for simple fracture and internal fixator (bridging) principle for the multifragmentary fracture.

\section{LCP as pure internal fixator (bridge plating)}

The LCP can be used as a pure locked internal fixator based on the principle of relative stability by bridging the fracture zone. Here, locking head screws are used exclusively. After indirect reduction, the complex type $\mathrm{C}$ fracture zone is not exposed but bridged by a long, locked plate. Preserving vascularity in combination with internal splinting allows rapid fracture healing with external callus formation. The fracture bone should be appropriately aligned before the LCP is applied. While temporarily, 
inserted conventional cortex screws may be used as a reduction aid or to approximate a large fragment, little or no contouring of the plate is needed.

The typical indications for this technique are: Multifragmentary fracture in the diaphysis and metaphysis. Open-wedge osteotomies (example- proximal tibia). Periprosthetic fracture. Delayed change from external fixator to definite internal fixation.

Using these different principles of fracture treatment leads to different types of fracture healing. Under certain circumstances, the two different principle of absolute and relative stability may be in compatible. Therefore, it is advisable to use only one of the two method in one fracture zone, either in a compression method or as internal fixator.

These locked internal fixators (PC fix, LISS, LCP) are ideal for the MIPPO technique of fracture fixation. The pre-conditions for internal fixation by MIPPO are: Indirect closed reduction without exposure of the fracture. Small incision for insertion of implants. Elastic bridging of fracture zone with a locked internal fixator (example: LISS, LCP). Implants with minimal bone contact. Slightly elevated plate from the bone surface to eliminate any miss match of the pre-contoured plate to the anatomy of the bone. Self drilling and self tapping locking head screws for mono-cortical insertion. Self tapping screws for bicortical insertion. Relative stability increases callus formation.

\section{METHODS}

This is the prospective study was carried out in department of Orthopaedics and Rehabilitation, RNT Medical College, Udaipur, Rajasthan from January 2020 till June 2021. The total number of cases studied were 25 with the youngest 20 years and oldest 70 years.

The intention of this dissertation was to study the treatment of proximal tibia fracture with locking compression plate using MIPPO technique to obtain a stable, painfree, mobile joint to prevent the development of osteoarthritis.

\section{Inclusion criteria}

Adult (aged over 18 years) both male and female. Fracture of less than 3 weeks duration.

\section{Exclusion criteria}

Patient aged below 18 years. Type IIIb compound fractures. Pathological fractures. Fractures which couldn't be reduce by MIPPO technique.

On admission demographic data was recorded and thorough history and clinical examination was done. We assessed the soft tissue injuries even in the closed fractures followed by radiological assessment of the fracture with Schatzker's classification.
As soon as the operation was planned, certain routine procedures were performed like: Use of preoperative antibiotics and continued till 5th post-operative day. Stabilize the patient haemodynamically and physical fitness for surgery was obtained. Preoperative planning for selection of plate, MIPPO technique, surgical approach either anteromedial or anterolateral according to the displacement of fracture. In our series, reduction done with manual traction and/or reduction clamp and operated with c-arm guidance. To check for any associated fracture. Informed consent of study subjects was obtained before enrolling him/her for the study.

We treated all patients with MIPPO. After alignment of the fracture by indirect reduction (using manual traction and reductuion clamp) the plate is introduced through a short incision beneath the skin, and pushed distally on the lateral aspect of proximal tibia. The bridging plate is initially fixed proximally, the alignment is checked using fluoroscopy and finally, the plate is fixed distally.

\section{Statistical analysis}

Performed using Statistical package social sciences (SPSS) version 18. An independent t-test and chi 2 test were used.

The primary difference with the locking compression plate is the method of locking head screw insertion. Here since the locking head of the screw has to get locked in the locking part of the combihole. The direction of the drilling has to be perfect. Hence drilling for all locking head screws has to be after fixing the screw in drill sleeve.

We also made sure that whenever using the non-locking regular screw in the fixation. They were inserted prior to the insertion of the locking screws.

\section{Postoperative}

In the immediate postoperative period care was given to the general condition, fluid balance, IV antibiotic and analgesics as per the protocol. This helped us to mobilize the patient faster.

\section{Mobilization}

Whenever stable internal fixation was achieved, the patient was mobilized after 72 hours after removal of the drains, for 2-3 days the range of motion allowed was 0-200, from the 5th day the range of motion was gradually allowed to be increased to 900 more after suture removal full range of movement was allowed.

Whenever there was doubt about the stable fixation. External splinting in the form of plaster of Paris slab was given for support and advised to do static quadriceps exercises. Continue passive motion exercise (CPM) were done daily with temporarily removal of slab under carefully supervision and splint reapplied. Partial weight 
bearing was delayed until 6 weeks and full weight bearing allowed after 12-16 weeks.

\section{Follow up}

The first follow up was usually between 4-6 weeks and later on patients were followed up at regular interval of 6 8 weeks till complete fracture union.

\section{During follow up}

The course of fracture healing was documented radiologically with minimum 6 weeks interval. The moment of complete healing was defined as radiologically complete bone regeneration at fracture site. Evaluation of any possible loss of reduction. Assessment and analysis of any complication. Knee score calculated at every follow up visit.

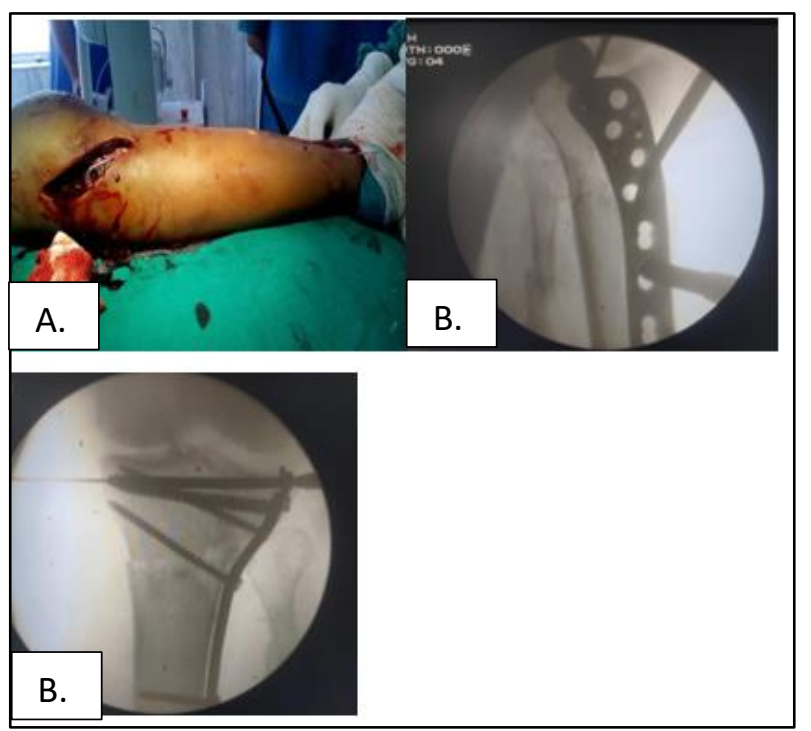

Figure 2: (A) Submuscular plate insertion and (B) Close reduction and plate fixation under fluoroscopy.

\section{RESULTS}

We studied 25 patients with 25 tibial proximal tibia fractures who were treated with locking compression plate.

Most of the patients belong to 21-30 years of age group who are more prone to RTA.

Most of our patients were male. It reflects the general population which visit our both outpatient as well as the emergency trauma section. It has shown that major preponderance of proximal tibia fracture is seen in male population. Who indulge themself in traveling because majority of morbidity is due to RTA.

In our series, there is a right sided predominance compared to the left side.
Table 1: Knee score (Insall modification- 1993).

\begin{tabular}{|c|c|}
\hline \multicolumn{2}{|l|}{ Additions } \\
\hline Pain & 50 (Maximum) \\
\hline \multicolumn{2}{|l|}{ Walking } \\
\hline None & 35 \\
\hline Mild or moderate & 30 \\
\hline Severe & 15 \\
\hline Stairs & 0 \\
\hline None & 15 \\
\hline Mild or moderate & 10 \\
\hline Severe & 5 \\
\hline ROM & 0 \\
\hline \multicolumn{2}{|c|}{ For every $8^{\circ}=1$ point } \\
\hline \multicolumn{2}{|c|}{ Stability } \\
\hline \multicolumn{2}{|l|}{ Median/lateral } \\
\hline $0-5 \mathrm{~mm}$ & 15 \\
\hline $5-10 \mathrm{~mm}$ & 10 \\
\hline$>10 \mathrm{~mm}$ & 5 \\
\hline \multicolumn{2}{|l|}{ Anterior /posterior } \\
\hline $0-5 \mathrm{~mm}$ & 10 \\
\hline $5-10 \mathrm{~mm}$ & 8 \\
\hline$>10 \mathrm{~mm}$ & 5 \\
\hline \multicolumn{2}{|l|}{ Deductions } \\
\hline \multicolumn{2}{|l|}{ Extension lag } \\
\hline None & 0 \\
\hline$<4$ degrees & -2 \\
\hline 5-10 degrees & -5 \\
\hline$>11$ degrees & -10 \\
\hline \multicolumn{2}{|c|}{ Flexion contracture } \\
\hline$<5$ degrees & 0 \\
\hline 6-10 degrees & -3 \\
\hline 11-20 degrees & -5 \\
\hline$>20$ degrees & -10 \\
\hline \multicolumn{2}{|l|}{ Malalignment } \\
\hline \multicolumn{2}{|c|}{$\begin{array}{l}\text { Upto } 5-10 \text { degrees } 0 \text { and if more then for every } 5^{\circ}=-2 \\
\text { points) }\end{array}$} \\
\hline \multicolumn{2}{|c|}{ Pain at rest } \\
\hline Mild & -5 \\
\hline Moderate & -10 \\
\hline Severe & -15 \\
\hline $\begin{array}{l}\text { Symptomatic plus } \\
\text { objective }\end{array}$ & 0 \\
\hline
\end{tabular}

In our series the majority of the fractures were found to be extraarticular as compared to intraarticular (Schatzker Type VI).

In our series in majority of fractures we used low profile $3.5 \mathrm{~mm}$ ) plate for fixation.

We used bridging type for 15 patients with fracture (Extraarticular) extending into metaphysical region and lack of purchase to the screw due to communication in metaphysical region. 
Table 2: Knee score.

\begin{tabular}{|ll|}
\hline Knee score & 100 (Maximum) \\
\hline Excellent & $80-100$ \\
\hline Good & $70-79$ \\
\hline Fair & $60-69$ \\
\hline Poor & Below 60 \\
\hline
\end{tabular}

Table 3: Age distribution.

\begin{tabular}{|lll|}
\hline $\begin{array}{l}\text { Age group } \\
\text { (years) }\end{array}$ & Number of patients & Percentage \\
\hline $\mathbf{1 8 - 2 0}$ & 1 & 4 \\
\hline $\mathbf{2 1 - 3 0}$ & 9 & 36 \\
\hline $\mathbf{3 1 - 4 0}$ & 6 & 24 \\
\hline $\mathbf{4 1 - 5 0}$ & 3 & 12 \\
\hline $\mathbf{5 1 - 6 0}$ & 5 & 20 \\
\hline$>$ 60 & 1 & 4 \\
\hline Total & 25 & 100 \\
\hline
\end{tabular}

Table 4: Sex distribution.

\begin{tabular}{|lll|}
\hline Sex & Number of patients & Percentage \\
\hline Male & 21 & 84 \\
\hline Female & 4 & 16 \\
\hline Total & 25 & 100 \\
\hline
\end{tabular}

Table 5: Laterality of fracture.

\begin{tabular}{|lll|}
\hline $\begin{array}{l}\text { Laterality of } \\
\text { fracture }\end{array}$ & Number of patients & Percentage \\
\hline Right & 17 & 68 \\
\hline Left & 8 & 32 \\
\hline Total & 25 & 100 \\
\hline
\end{tabular}

Table 6: Type of fracture and percentage of cases.

\begin{tabular}{|lll|}
\hline Type of fracture & $\begin{array}{l}\text { Number of } \\
\text { patients }\end{array}$ & Percentage \\
\hline Intraarticular & 10 & 40 \\
\hline Extraarticular & 15 & 60 \\
\hline Total & 25 & 100 \\
\hline
\end{tabular}

Table 7: Plate used.

\begin{tabular}{|lll|}
\hline Plate & Number of patient & Percentage \\
\hline $\mathbf{3 . 5} \mathbf{~ m m}$ & 14 & 56 \\
\hline $\mathbf{4 . 5} \mathbf{~ m m}$ & 11 & 44 \\
\hline Total & 25 & 100 \\
\hline
\end{tabular}

Combined type was used in 10 patients were articular reconstruction is essential and need protection from collapsing in postoperative period.

Out of 25 cases treated, 13 cases gave excellent result 9 cases came out with good result, fair in 2 cases and 1 case of poor results.
We had no cases of any purely implant related complication like screw loosening, screw breakage, plate failure.

Table 8: Principle of fixation.

\begin{tabular}{|lll|}
\hline $\begin{array}{l}\text { Principle of } \\
\text { fixation }\end{array}$ & $\begin{array}{l}\text { Number of } \\
\text { patients }\end{array}$ & $\begin{array}{l}\text { Percentag } \\
\text { e }\end{array}$ \\
\hline Bridging & 15 & 60 \\
\hline Combined & 10 & 40 \\
\hline Total & 25 & 100 \\
\hline
\end{tabular}

Table 9: Clinical results.

\begin{tabular}{|lll|}
\hline Clinical result & Number of patients & Percentage \\
\hline Excellent & 13 & 52 \\
\hline Good & 9 & 36 \\
\hline Fair & 2 & 8 \\
\hline Poor & 1 & 4 \\
\hline Total & 25 & 100 \\
\hline
\end{tabular}

Table 10: Complication.

\begin{tabular}{|l|l|}
\hline Complication & $\begin{array}{l}\text { Number of } \\
\text { patients }\end{array}$ \\
\hline Knee joint stiffness & 4 \\
\hline Postoperative loss of reduction & 0 \\
\hline Infection & 2 \\
\hline Varus deformity & 0 \\
\hline Knee instability & 0 \\
\hline
\end{tabular}

Average time for union of fracture was 20 weeks (range from 16-24 weeks).

One patient with knee joint stiffness is due to associated with ipsilateral intercondylar fracture of femur and other with associated ipsilateral shaft femur and patella fracture. Another 3 patients with knee joint stiffness is due to lack of postoperative mobilization. Two patients developed deep infection of operative site and treated with antibiotic and above knee pop cast applied later, fracture united at 24 weeks.

\section{Associated injuries}

Ipsilateral fracture shaft femur treated with interlocking nail, ipsilateral segmental tibia treated with LCP for lower end tibia by MIPPO and fracture patella managed conservatively. Ipsilateral fracture supracondylar femur treated with ORIF and cobra plate. Ipsilateral fracture pott's fracture patella managed close reduction and fixation with percutaneous k-wire.

\section{DISCUSSION}

Tibial plateau fractures, one of the commonest intra articular fractures, incidence of these fractures are 
increasing regularly due to RTA and at the same time surgical treatment options for the same are also being modified continuously. Any fracture around the weight bearing joint like knee joint is of paramount importance as would result in significant morbidity and quality of life. ${ }^{19}$

Hence the treatment of tibial plateau fractures has become a challenge for the orthopaedic surgeons.

To overcome this difficulties and to early restoration of strength of bone and function of knee joint with minimal injury to soft tissue the innovators developed new technologies called MIPPO and locking compression plate system. ${ }^{29}$

Keeping our aims of the study at high, we presented the clinical study of surgical treatment of 25 tibial plateau fractures. The analysis of the results were made in terms of age of patients, sex distribution, Laterality of fracture, mode of violence, analysis of the types, method of reduction and fixation, principle of LCP fixation, surgical approach and complications.

The majority of fracture occur between the age of 19-67 years with maximum incidence being involving the productive age group 21-30 years (36\%) with average of 38.95 years. Boune in 1981 also found that the majority of the patients are aged between 15-55 years with an average of 38.5 years. Correlated well with the study, Seppo also showed age incidence 20-60 years with an average of 39.8 years which correlates with the present study.

In our series majority of the patients were males $84 \%$, this can be attributed to our Indian setup where the female population largely work indoor and do not travel much.

In our study the commonest mode of injury being the road traffic accident $80 \%$ other being fall from height $20 \%$. There was difference in the laterality of the fracture. The right tibia was affected in $68 \%$ and left tibia in $32 \%$ of cases.

In this series we studied 25 cases out of them most patient have extra-articular fractures and other fall into type VI schatzker's classification. Different authors use different criteria for the surgical management of these fractures (Intra-articular). SEPPO E. Honkonen conducted 130 tibial plateau fractures taking into consideration of: Condylar widening of $>5 \mathrm{~mm}$, lateral condyle step off $>3$ $\mathrm{mm}$, all medial condylar fracture.

In our series the indications for the surgery were the same standard indications as for the tibial plateau fractures in intra-articular extension. $3 \mathrm{~mm}$ depression was considered as indications for surgery in our series.

In our series we used combined (Compression and bridging) principle of fixation in 10 patients $40 \%$ and achieved good articular reconstruction and protection from collapsing during post operative period. We used bridging type of principle of fixation in 15 patients $60 \%$ in metapyseal comminution fractures and osteoporotic patient where bone graft was needed. We have not done bone graft in these patient as LCP implant system provide good fixation and prevent collapse of fracture during postoperative period.

In our series we approached with antero lateral incision in all patients this approach need less soft tissue stripping from bone, can contour plate to bone appropriately and easy to perform MIPPO technique.

In our series we had no cases of any purely implant related complications and average time for union of fracture was 18 weeks.

In our series one patient develop knee stiffness due to associated ipsilateral fracture of femoral condyle. With physiotherapy $\mathrm{HE}$ regain $\mathrm{ED} 60^{\circ}$ of flexion and had poor result.

Another patient with ipsilatral fracture shaft femur, ipsilateral segmental tibia and patella present with knee joint stiffness treated with physiotherapy and regain $90^{\circ}$ of flexion and had good result.

Another patient present with knee stiffness because of prolonged casting as he had associated head injury and was irritable. At end of 3 months of postoperative period he was treated with physiotherapy and he regained a range of movement from complete extension to $90^{\circ}$ of flexion and had fair result.

Another two patients developed knee stiffness due to lack of physiotherapy had fair results.

In our series one patient develop deep infection by 7 th postoperative day he was treated with incision and Drainage and IV antibiotics (Piperacillin-tazobactum and amikacin), subsequently infection was controlled and fracture union occurred at an end of 24 weeks postoperatively but with stiff knee. Another patient developed superficial skin infection on medial aspect of proximal tibia and treated with IV antibiotics and had fracture union after 24 weeks and had good results.

The period of immobilization was again individualized depending on the security of stable fixation. The benefits of early knee motion include reduce of knee stiffness and improved cartilage healing (regeneration) and promote good callus formation and remodelling.

In spite of all these complications we are able to achieve $52 \%$ excellent result and $36 \%$ good result (overall $88 \%$, acceptable results) with standard institutional surgical care. In addition, we have $8 \%$ fair and $4 \%$ poor results in term of functional outcome. These results are comparable with other documented standard studies. 


\section{CONCLUSION}

At the end of our study, following conclusions could be drawn from the treatment of proximal tibial fracture with locking compression plate. Proximal tibial fractures are increasing with the increase in Road traffic accidents. These fracture need optimum treatment as most of them involved the productive men. Preoperative soft tissue status and their repair at right time Significantly changes the outcome. The anchorage of the locking head screw was found to be excellent even in osteoporotic bone. Drilling the holes for the locking head screw should always be through a screw-in drill sleeve. While bridging a fracture, care must be taken to select a strong plate and leave atleast 2-3 plate hole, without inserting screws over the fracture. Thisprevents the stress concentration and achieves an elastic fixation which is very essential for secondary fracture union. Even in osteoporotic bone, bone graft is not essential for defect in metaphyseal region as LCP internal fixator system act as single implant and prevent collapse of fracture intraoperatively and postoperatively subsequently bone deficient will heal by callus formation. When LCP used as combined principle of fixation we can reconstruct tibial plateau with compression and prevent it from collapse by bridging principle. In our study LCP as a compression plate was not as good as combined and bridge plating type of fixation. Fractures treated with MIPPO healed rapidly by secondary fracture union and hence achieving strong bone union across the fracture at a much earlier time compared to open reduction and internal fixation due to less soft tissue injury leads to minimal blood supply interruption to proximal tibia. Thus, we conclude that the locking compression plate system with indirect reduction and minimally invasive procedure act as an good biological fixation including difficult fracture situations. But this also involve the risk that may occur unless properly planned preoperatively and follow guided principles intraoperative and postoperatively subsequently bone deficient will heal by callus formation. When LCP used as combined principle of fixation we can reconstruct tibial plateau with compression and prevent it from collapse by bridging principle. Fractures treated with MIPPO healed rapidly by secondary fracture union and hence achieving strong bone union across the fracture due to less soft tissue injury leads to minimal blood supply interruption to proximal tibia. Thus, we conclude that the locking compression plate system using minimally invasive percutaneous plate osteosynthesis act as an good biological fixation including difficult fracture situations. But this also involve the risk that may occur unless properly planned preoperatively and follow guided principles intraoperatively.

\section{ACKNOWLEDGEMENTS}

I am grateful to my co-authors for support, assessment, collection of data for this project. also thankful to our radiology team of RNT medical college and hospital; Udaipur Rajasthan.
Funding: No funding sources

Conflict of interest: None declared

Ethical approval: The study was approved by the institutional ethics committee

\section{REFERENCES}

1. Perry CR. Fractures of tibial plateau. Instr Course Lect. 1994;43:119-26.

2. George A, Brown, Spraque. Cast bracetreatment for plateau and bicondylar fracture of tibia. Clin Orthop. 1976;119:184.

3. Bennett WF, Browner B. Tibial Plateau Fractures: A Study of Associated Soft Tissue Injuries. J Orthop Trauma. 1994;8:183-8.

4. Apley A. Fractures of the lateral tibial condyle treated by skeletal traction and early mobilization. J Bone Joint Surg. 1956;38:699-708.

5. Wagner M. General principles for the clinical use of the LCP. Injury. 2003;34(2):B31-42.

6. Westmoreland GL, Mclaurin TM, Hutton WC. Screw pullout strength: A biomechanical comparison of large fragment and small fragment fixation in tibial plateau. J Orthop Trauma. 2002;16:178-81.

7. Ali AM, el Shafie M, Willet KM. Failure of fixation of tibial plateau fracture. $\mathrm{J}$ Orthop Trauma. 2002;16:323-9.

8. Mallik AR, Covall DJ, Whitelaw GP. Internal versus external fixation of bicondylar tibial plateau fractures. Orthop Rev. 1992;21:1433-6.

9. Moore TM, Patzakis MJ, Harvey JP. Tibial plateau fractures: definition, demographics, treatment rationale, and long-term results of closed traction management or operative reduction. J Orthop Trauma. 1987;1:97-119.

10. Sommer C, Gautier E, Muller M. For clinical application of the LCP. Injury. 2003;34(2):B43-54.

11. Carlson DA. Posterior bicondylar tibial plateau fractures. J Orthop Trauma. 2005;19:73-8.

12. Stannard JP, Wilson TC, Volgas DA, Alonso JE. The less invasive stabilization system in the treatment of complex fractures of the tibial plateau: short-term results. J Orthop Trauma. 2004;18:552-8.

13. Bucholz RW, Brumback RJ. Fractures of the Shaft of the Femur, In: Rockwood and Green's Fractures in Adults, C.A. Rockwood Jr, D.P. Green, R.W. Bucholz, J.D. Heckman (Ed.). Lippincott-Raven Publishers, Philadelphia, New York. 1996;1827-910.

14. Krettek C, Schandelmaier P, Miclau T, Tscherne H. Minimally invasive percutaneous plate osteosynthesis (MIPPO) using the DCS in proximal and distal femoral fractures. Injury. 1997;28(2):A2030.

15. Wenda K, Runkel M, Degreif J, Rudig L. Minimally invasive plate fixation in femoral shaft fractures. Injury. 1997;28(1):A13-9.

16. Krettek C, Schandelmaier P, Miclau T, Bertram R, Holmes W, Tscherne H. Transarticular joint reconstruction and indirect plate osteosynthesis for 
complex distal supracondylar femoral fractures. Injury. 1997;28(1):A31-41.

17. Krettek C, Gerich FT, Miclau TH. A minimally invasive medial approach for proximal tibia. Injury. 2001;32(1):4-13.

18. Sirbu P, Mihaila R, Ghionoiu G, Bruja R, Asaftei R. Minimally invasive plate osteosynthesis (MIPPO) in proximal and distal fractures of tibia. Proceedings of 7th European Trauma Congress. 2006;49-54.

19. Cole PA, Zlowodzki M, Kregor PJ. Treatment of proximal tibia fractures using the less invasive stabilization system: surgical experience and early clinical results in 77 fractures. J Orthop Trauma. 2004;18:528-35.

20. Stoffel K, Dietaru. Biomechanical testing of the LCP how can stability in locked internal fixator be controlled. Injury. 2003;34(2):B11-9.

21. Goyal KS, Shalak AS, Marcus RE. Analysis of anatomic periarticular tibial plate fit on normal adults. Clin Orthop Rel Res. 2007;461:245-57.

22. Matityahu A, Krettek C, Miclau T III. Evolving concepts in plate fixation. In: Stannard JP, Schmidt AH, Kregor PJ, eds. Surgical treatment of orthopedic trauma. Philadelphia. Thieme Medical Publishers. 2007;58-64.

23. Palmer I. Compression fracture of lateral tibial condyle and their treatment. J Bone \& Joint Surg. 1939;2(AM):674.

24. Apley Graham A., Pyrford, England, Fractures Of The Lateral Tibial Condyle Treated By Skeletal Traction And Early Mobilisation. 1956;38(3):699708.

25. Lansinger O, Bergman B, Korner L. Tibial condylar fractures. A twenty-year follow-up. J Bone Joint Surg Am. 1986;68:13-19.

26. Moore TM, Patzakis MJ, Harvey JP: Tibial plateau fractures: Definition, demographics, treatment rationale, and long-term results of closed traction management or operative reduction. J Orthop Trauma. 1987;1:97-119.

27. Rasmussen PS. Tibial condylar fractures. Impairment of knee joint stability as an indication for surgical treatment. J Bone Joint Surg Am. 1973;55:1331-50.

28. Schatzker J, McBroom R, Bruce D. The tibial plateau fracture. The Toronto experience 1968-1975. Clin Orthop Relat Res. 1979;1973;94-104.

29. Tscherne H, Lobenhoffer P. Tibial plateau fractures. Management and expected results. Clin Orthop Relat Res. 1993;87-100.

30. Lachiewicz MP, Lachiewicz PF. Are the Relative Indications for Revision Total Knee Arthroplasty Changing? J Surg Orthop Adv. 2009;18(2):74-6.

31. Houben PF, van der Linden ES, van den Wildenberg FA, Stapert JW. Functional and radiological outcome after intra-articular tibial plateau fractures, Injury (impact factor: 1.98). 1997;28(7):459-62.

32. Waddell JP, Johnston DW, Neidre A. Fractures of the tibial plateau: a review of ninety-five patients and comparison of treatment methods. $\mathbf{J}$ Trauma. 1981;21(5):376-81.
33. Schatzker J, Schulak DJ. Pseudarthrosis of a tibial plateau fracture: Report of a case. Clin Orthop. 1979;145:146-9.

34. Shrestha BK, Bijukachhe B, Rajbhandary T, Uprety S, Banskota AK. Tibial plateau fractures: four years review at B \& B Hospital, Kathmandu Univ Med J (KUMJ). 2004;2(4):315-23.

35. Volpin G, Dowd GS, Stein H, Bentley G. Degenerative arthritis after intra-articular fractures of the knee. Long-term results. Journal of Bone and Joint Surgery. 1990;72(4):634-8.

36. Honkonen SE. Degenerative arthritis after tibial plateau fractures. J Orthop Trauma. 1995;9:273-77.

37. Duwelius PJ, Rangitschm MR, Colville MR, Woll TS. Treatment of Tibial Fractures by Limited Internal Fixation. Clin Orthop. 1997;339:47-57.

38. Gausewitz S, Hohl M. The significance of early motion in the treatment of tibial plateau fractures. Clin Orthop. 1986;202:135-8.

39. Gualtieri G, Hendriks M, Gualtieri I, Prosperi P, Fracture of the tibial plateau: results of surgical treatment. Chir Organi Mov. 1989;74(1-2):13-20.

40. Barei DP, Nork SE, Mills WJ. Functional outcomes of severe bicondylar tibial plateau fractures treated with dual incisions and medial and lateral plates. J Bone Joint Surg Am. 2006;88:1713-21.

41. Carlson DA. Posterior bicondylar tibial plateau fractures. J Orthop Trauma. 2005;19(2):73-8.

42. Wang SQ, Gao YS, Wang JQ, Zhang CQ, Mei J, Rao ZT. Surgical approach for high-energy posterior tibial plateau fractures, Indian J Orthop. 2011;45(2):125-31.

43. Barei DP, O'Mara TJ, Taitsman LA, Dunbar RP, Nork SE. Frequency and fracture morphology of the posteromedial fragment in bicondylar tibial plateau fracture patterns. J Orthop Trauma. 2008;22:176-83.

44. Oestern HJ, Tscherne H. Pathophysiology and classification of soft tissue injuries associated with fractures. In: Fracture with soft tissue injuries. Tscherne H, Gotzen L, editors. New York: Springer. 1984;6.

45. Mikulak SA, Gold SM, Zinar DM. Small wire external fixation of high energy tibial plateau fractures. Clin Orthop. 1998;(356):230-8.

46. Egol KA, Capla EL, Wolinsky PL. Bridging External Fixation for High Energy Proximal Tibia Fractures: Results of a Prospective Protocol. In: O.T.A. annual meeting, 2003, Salt Lake City, UT.

47. Ryan KJ, Malkani AL, Roberts CS, Seligson D, Crawford CH, Smith L. Treatment of bicondylar tibia plateau fractures using locked plating versus external fixation, Orthopedics. 2009;32(8).

48. Young MJ, Barrack RL. Complications of internal fixation of tibial plateau fractures. Orthop Rev. 1994;23(2):149-54.

49. Ballmer FT, Hertel R, Nötzli HP. Treatment of tibial plateau fractures with small fragment internal fixation: a preliminary Report. J Orthop Trauma. 2000;14(7):467-74. 
50. Westmoreland GL, McLaurin TM, Hutton WC. Screw pullout strength: a biomechanical comparison of large-fragment and small-fragment fixation in the tibial plateau, J Orthop Trauma. 2002;16(3):178-81.
Cite this article as: Meena DK, Choubisa R, Juneja J, Sharma A. Functional and clinical outcome of MIPPO anterolateral plating for proximal tibia fracture both proximal one third and coronal intrarticular fracture. Int J Res Orthop 2021;7:1127-38. 